\title{
Evaluating Horizontal Multistage Fracture Well Placement in Low \\ Permeability Reservoir
}

\author{
WANG Chang ${ }^{1, a}$, YU Yuan ${ }^{1, b}$, Zhou Zhi ${ }^{1, c}$ \\ ${ }^{1}$ School of Petroleum Engineering, Yangtze University, Wuhan, 430100, China; \\ awjczjwz@163.com, ${ }^{\mathrm{b}} 369624446 @ q q . c o m,{ }^{\mathrm{c}} 525257196 @ q q . c o m$
}

Keyword:Low permeability reservoir, Sensitivity experiment, Well spacing optimization

\begin{abstract}
Abstact.Well spacing is a critical factor to figure out when planning to drill new wells in low permeability reservoirs. In this paper, horizontal multistage fractured well spacing is optimized for several scenarios in $\mathrm{H}$ reservoir using PEBI grips. To find the optimum well spacing, sensitivity analyses are carried out first to find the most influential fracturing parameters. Orthogonal experiment is used to scheme scenarios which incorporates sensitive parameters. The results show that fracture number and fracture conductivity exert significant impacts on oil recovery. The best spacing for the finite reservoir is $6000 \mathrm{ft}$.
\end{abstract}

\section{Introduction}

Fracturing technology has been developing rapidly in recent years. Both the size and sophistication of field treatments have increased dramatically. The development of low permeability reservoir can utilize advantages of fracturing technology[1]. Compared to normal fracturing technology, horizontal, multistage fractured wells increases the reservoir contact and effective drainage area and provides a highly conductive path to the wellbore[2]. In this study, $\mathrm{H}$ oilfield would be analyzed. $\mathrm{H}$ oilfield is a typical low permeabilitytight sandstone reservoir. There are three major depositional systems classified for the depression: salt lake delta, underwater fan and salt lake subfacies. $\mathrm{H}$ oilfield was developed from 1977. At present, the current oil recovery has been up to $31.84 \%$ and water cut for overall wells has reached up to $61.3 \%$. Although the recovery and water cut of the oilfield is all higher, there is still some remaining oil in its boundary and corner zones, multi-directional water squeezing zones and local low permeability zones, and reservoir engineers should target on these potential zones. PEBI gridsis used to optimize well placement study. PEBI grids is capable of controlling errors of flow calculation, and can be used to model structurally highly complex reservoirs in two and three dimensions. Besides, flow feature of the multistage fractures can be modeled better by PEBI grids[3]. Non-Darcy flow is considered in the simulation. In this study, mature commercial simulator is used. The basic parameters for this model are described in Table1.

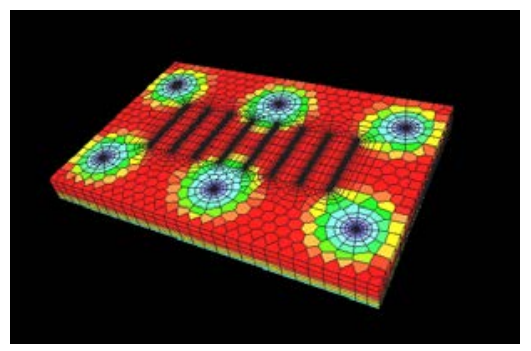

Fig. 1 PEBI grids model 
Table 1Settled reservoir, oil, water, well and hydraulic fracture data

\begin{tabular}{ll}
\hline Parameter & Value \\
\hline Porosity, $\varphi(\%)$ & 16 \\
Reservoir permeability, k(md) & 17 \\
Reservoir depth, $(\mathrm{ft})$ & 7000 \\
Reservoir thickness, $(\mathrm{ft})$ & 30 \\
Rock compressibility, cf(psi-1) & $3.0 \mathrm{E}-6$ \\
Reservoir temperature, Tr( $\left.{ }^{\circ} \mathrm{F}\right)$ & 200 \\
Reservoir vertical-to-horizontal anisotropy ratio & 0.1 \\
Oil viscosity, $\mu$ o (cp) & 3.5 \\
Water viscosity, $\mu$ o (cp) & 0.30 \\
Horizontal well length, Lh(ft) & 3000 \\
Wellbore radius, rw(ft) & 0.3 \\
Average fracture width, Wf(inch) & 0.25 \\
\hline
\end{tabular}

\section{Sensitivity Analysis}

Some fracture parameters are chosed to check their influence on a horizontal well's produce performance. The results show that fracture half-length, fracture number and fracture conductivity are key parameters for optimization well spacing. Thus sensitivity experiment is carried out to examine these parameters' sensibility. Pragmatic range of these parameters will be selected based on $\mathrm{H}$ oilfield. Cumulative oil production is used to evaluate the difference caused by fracture parameters. In order to eliminate well interference, simulation runs on a single well model within a $20000 \times 20000 \mathrm{ft}$ reservoir model.

Table 2 Parameters of hydraulic fracture

\begin{tabular}{ll}
\hline Parameter & Value \\
\hline Fracture half-length, $\mathrm{X}_{\mathrm{f}}(\mathrm{ft})$ & $100,200,300$ \\
Fracture number, $\mathrm{N}_{\mathrm{f}}$ & $4,8,12$ \\
Fracture conductivity, $\mathrm{C}_{\mathrm{f}}(\mathrm{md} . \mathrm{ft})$ & $10,100,500$ \\
\hline
\end{tabular}

Fracture Characteristics. Number of fracture and fracture half-length are considered in the sensitivity experiment.The range of $\mathrm{X}_{\mathrm{f}}, \mathrm{N}_{\mathrm{f}}$ and $\mathrm{C}_{\mathrm{f}}$ are presented in Table2. In the sensitivity experiment, the simulation runs were simulated with model data provided in Table1 along with the following properties: $\mathrm{X}_{\mathrm{f}}$ of $200 \mathrm{ft}, \mathrm{N}_{\mathrm{f}}$ of $8, \mathrm{C}_{\mathrm{f}}$ of 100 .

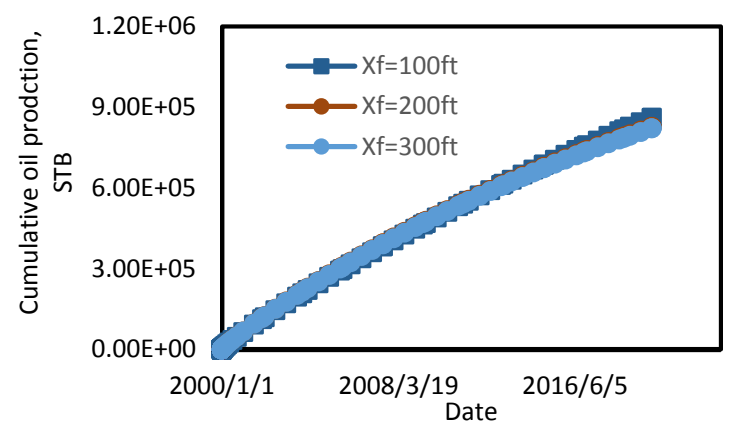

Fig.2 Sensitivity results of different fracture length

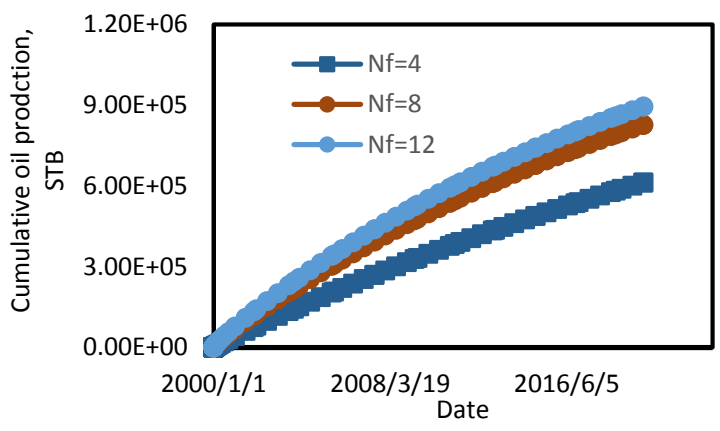

Fig. 3 Sensitivity results of different fracture number 
The simulation results of sensitivity examination for fracture half-length areshowed in Fig2. The plots indicate that fracture half-length cannot exert significant impacts on reservoir recovery.In contrast tolong distance of pressure drop, fracture half-length is comparatively short. Thus Fig.2 shows mild difference among three scenarios.Hence, the relation between fracture half-length and cumulative oil production should be neglected in the later study.

Fig. 3 describes cumulative oil production vs. time for 4,8 and 12 fractures. The results show that the numbers of fractureaffect oil production. Compared to normal horizontal well, horizontal multistage fracture well promotes oil production tremendously. However, the difference of cumulative production will be decreased when fracture number are augmented to an extent. When horizontal well length is fixed, there is a critical value offracture number exists. Field engineers should spend least cost to obtain highest oil recovery. All in all, number of fracture should be considered in optimization study.

Furthermore, the last fracture property considered for sensitivity study is fracture conductivity. Fig.4 shows that larger cumulative production is obtained from horizontal wells with higher fracture conductivity. Thus, when fracture conductivity is low, pressure drop is not enough for oil to flow toward the fractures. Fracture conductivity is considered as a sensitivity variable in optimization study.

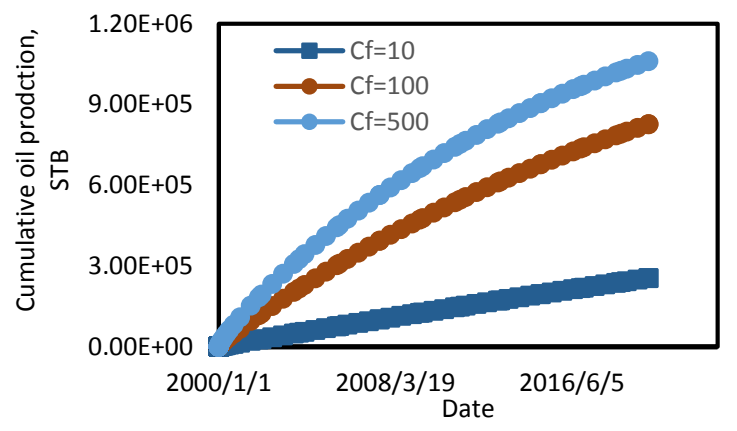

Fig. 4 Sensitivity results of differentfracture conductivity

\section{Well Spacing Optimization}

Well spacing is a crucial parameter which would be considered in horizontal fracture multistage well design. Well spacing should be studied to obtain optimum production and economic benefit. In this well spacing study, five-point well pattern is used, since five-point well pattern is typical develop well pattern for low permeability reservoir. As what have been discussed above, fracture number and fracture conductivitywould be considered in the optimization study. The well distance about 4000, 6000 and 10000ftare considered in the simulation. These models would be run in 50000 $\times 50000 \mathrm{ft}$ reservoir model.Orthogonal experimental design which could analyze effect of several factors comprehensively isgiven to plan different scenarios.These scenarios and simulation results are showed in Table3.

The results of orthogonal experimentare analyzed via visual analysis method. The average value of fracture number and fracture conductivity prove that the sensitivity experiment's results are correct. The average cumulative production of 4000, 6000 and $10000 \mathrm{ft}$ well distanceare 3444048, 3472100, 3069794 STB, Theresultsof visual analysis indicates that cumulative oil production of 4000 and $6000 \mathrm{ft}$ well distance are approximately equal values. The reasons for that aredue to small well distance would lead to several wells sharing drainage area together and well interference would be caused. And short well distance would cause that wells could not deplete what they arecapable of. 
No matter of economic concerns or technological concerns, compared to the scenario that well distance is $4000 \mathrm{ft}, 6000 \mathrm{ft}$ well distance is more suitable for the reservoir. On the other hand,dead oil zone would be generated when well spacing is too large.And injection control area cannot cover horizontal well completely. Thus well recover efficiency have not been maximized. That is the reason why cumulative production of $10000 \mathrm{ft}$ well distance was lower than $6000 \mathrm{ft}$ well distance.

\begin{tabular}{lllll} 
& \multicolumn{4}{c}{ Table3 Scenarios of orthogonal experiment } \\
\hline & well distance(ft) & $\mathrm{C}_{\mathrm{f}}(\mathrm{md} . \mathrm{ft})$ & $\mathrm{N}_{\mathrm{f}}$ & $\begin{array}{l}\text { cumulative } \\
\text { production(STB) }\end{array}$ \\
\hline scenario1 & $4000(1)$ & $10(1)$ & $4(1)$ & 894558 \\
scenario2 & 4000 & $100(2)$ & $8(2)$ & 4249514 \\
scenario3 & 4000 & $500(3)$ & $12(3)$ & 5188076 \\
scenario4 & $6000(2)$ & 10 & 12 & 1343007 \\
scenario5 & 6000 & 100 & 4 & 4523982 \\
scenario6 & 6000 & 500 & 8 & 4549313 \\
scenario7 & $10000(3)$ & 10 & 8 & 1640543 \\
scenario8 & 10000 & 100 & 12 & 2809481 \\
scenario9 & 10000 & 500 & 4 & 4759360 \\
\hline average value of(1) & 3444048 & 1292702 & 2751117 & \\
average value of (2) & 3472100 & 3860991 & 3450626 & \\
average value of (3) & 3069794 & 4832249 & 3784200 & \\
\hline
\end{tabular}

\section{Conclusion}

Optimum well spacing is strongly governed by fracture properties. Simulation results shows that fracture number and fracture conductivity are critical to optimum well spacing. Nevertheless, fracture half-length doesn't play a significant role in optimization. The orthogonal experiment results indicated $6000 \mathrm{ft}$ well distance are most suitable scheme among those scenarios. Too large well distance generates dead oil zone and is hard for injection well plays its role effectively. Too small well distance causes well interference and leads to contracted overall drainage area.

\section{References}

[1]A. Settari, H.S. Price, Simulation of Hydraulic Fracturing in Low-Permeability Reservoirs, J. Society of Petroleum Engineers. 24 (1984) 141-152.

[2] M. A. Alghannam, Z. Rahim, S. Aramco, Optimizing Spacing of Horizontal Multistage Fractured Wells in Gas Reservoirs, Abu Dhabi International Petroleum Exhibition and Conference, Abu Dhabi, UAE, 10-13 November, 2014, pp.70-81.

[3] M. J. Mlacnik, A. W. Harrer, Z. E. Heinemann, Locally Streamline-Pressure-Potential-Based PEBI Grids, SPE Reservoir Simulation Symposium, Houston, USA, 3-5 February, 2003, pp.29-34. 